\title{
Teaching
Anthropology
}

2021, Vol. 10, No. 3. pp 1-13.

\section{Navigating interdisciplinarity: negotiating discipline, embodiment, and materiality on a field methods training course.}

\author{
Rebecca Rotter ${ }^{1}$, Laura Jeffery ${ }^{1}$, Luke Heslop ${ }^{2}$. \\ ${ }^{1}$ University of Edinburgh, $U K,{ }^{2}$ Brunel University, $U K$.
}

\begin{abstract}
This article elucidates some of the opportunities and challenges of interdisciplinary collaboration in teaching, drawing on our participant observation as both instructors of anthropological methods and honorary students of marine ecology and geomorphology methods on a research training field course. We argue that interdisciplinary methods training offers educators opportunities for self-reflexivity, recognition of the taken-for-granted aspects of our knowledge, and improved communication of the value of our work to others. However, we also show how decisions about course structure can reinforce disciplinary boundaries, limiting inter-epistemic knowledge production; how one epistemological approach may overshadow others, hindering interdisciplinary learning; and how methods training involves tacit and embodied knowledge and mastery of material methods, requiring repetition and experimentation. We offer insights into how we as educators can improve our communication of the value of anthropology and its methods. First, instructors in any discipline should develop an awareness of how their tacit knowledge affects the pedagogical process. Second, instead of enskilling instructors to teach a variety of methods, it may be more beneficial for instructors to teach their own areas of expertise, in dialogue and collaboration with other disciplines. Third, interdisciplinary courses must be carefully planned to allow equal participation of different disciplines, so that anthropology is understood on its own terms and embedded in the course from the outset.
\end{abstract}

Keywords: Research methods; training; interdisciplinary; embodiment; materiality; knowledge.

\section{"Around the Island"}

After ten days together at a marine research centre on one island, our group of four staff and fifteen students visited another island in a different atoll. The geologist sent us to get changed into appropriate clothing and gather appropriate data collection equipment for a walk "around the island". We anthropologists prepared for a walk through the village: long trousers, flip-flops, and a backpack containing water, a notebook, a pen, and a mobile phone. We were surprised when the geologist set off down to the beach rather than the road towards the village. It soon became apparent that our attire and equipment were unsuitable for what became a very wet walk along the beach, through matted vegetation above the shoreline, around coconut trees lying nearly horizontal in the water, and, at the most inaccessible stages, on jagged karst rock in $75 \mathrm{~cm}$ deep ocean. It took an hour to reach the tip of the island, where we encountered a family who had come by boat rather than braving the thick vegetation. The question of how on earth we anthropologists could have failed to glean that from a geologist's perspective a walk "around the island" would mean a walk not around the inhabited parts of the island but rather around the perimeter of the island inspired us to critically reflect on interdisciplinarity in practice.

\section{Introduction}

This paper draws on our participant observation as instructors of anthropological methods and honorary students of marine ecology and geomorphology methods on an interdisciplinary research training field course within a University of Edinburgh School of GeoSciences Taught Masters programme in Marine Systems and Policies. In its early days the programme approached marine systems through three integrated spheres: the natural, policy, and built systems, and aimed to help students understand diverse marine ecosystems, tensions between ocean conservation and marine development, and policy-making to protect coastlines and the global ocean. As an expressly interdisciplinary programme it sought to move beyond traditional disciplinary paradigms 
and instead integrate diverse approaches to learning, problem solving, and critical thinking to respond to marine challenges. Applicants required an undergraduate degree in natural sciences, social sciences or engineering, and over the course of two semesters, students took compulsory courses in geosciences and optional courses in geosciences, law, engineering, and social sciences.

We participated in the first two annual Marine Field Methods in Research and Practice courses at the University of Milano-Bicocca's Marine Research and Higher Education (MaRHE) Center on the island of Magoodhoo in Faafu Atoll in the Republic of Maldives, chosen as an ideal location for environmental research on pristine tropical ecosystems. ${ }^{\text {T }}$ The course used a socio-ecological systems approach to study ecological and social aspects of small island ecosystems that face climate change and are trying to balance both conservation and "bluegrowth" development goals. It covered scientific methods, including basic marine ecology and marine geology quantitative field analysis methods in a mangrove/sea grass/coral reef setting, and social science methods such as interviews, participant observation, and focus groups with locals, academics, and representatives of government and NGOs, on marine development challenges and opportunities. ii The teaching staff included marine ecologists, marine biologists, geologists, and anthropologists. ${ }^{i i i}$ The anthropologists who shared the core social science teaching load adopted "an ethnographic sensibility in our teaching" (Mills and Spencer, 2011:1) and undertook participant observation as students of marine ecology and geomorphology methods.

In this paper, we explore our own assumptions and practices in transmitting our (anthropological) disciplinary knowledge and methods to students and colleagues, and self-critically employ anthropological methods to understand the assumptions and practices of other disciplines. We elucidate some of the challenges of pedagogical collaboration between science disciplines and anthropology. Several studies have identified a lack of pedagogical culture, literature, and interdisciplinary context surrounding teaching mixed methods (Hesse-Biber, 2015; Nind, Kilburn and Luff, 2015). Hesse-Biber (2015) argues that in order to improve mixed methods teaching and respond to the challenges students face - such as how different approaches meet different research objectives, and how to integrate apparently incompatible paradigmatic stances - instructors should be willing to undertake extensive training in theory and methods, gain first hand experience in conducting mixed methods projects, move "out of their theory/methods comfort zones" (2015: 474), and develop "interdisciplinary teambased research methods courses" (2015: 476). By highlighting the challenges that instructors face in developing methodological expertise in disciplines that are not their own, we propose a contrasting approach. We argue that instead of enskilling instructors to teach a variety of methods, it may be more beneficial for instructors to teach their own areas of expertise, in dialogue with other disciplines. While teaching their own specialisms, instructors should pursue what Wegerif calls a "dialogic space": a shared space of mutual resonance where distinct perspectives interact and entangle (Wegerif, 2017). This opening of a dialogic space is essential to the possibility of learning something new (Wegerif and Mercer, 1997). Unlike studies that focus on course structure, learning resources, and the attainment of proficiency in theoretical and conceptual matters (Hesse-Biber, 2015), we examine practical methodological training and the mastery of tools and techniques in multiple settings, which allows us to identify pedagogical issues surrounding embodied knowledge and skills development. We argue that instructors in any discipline should develop an awareness of how their tacit knowledge affects the pedagogical process.

In the first section we describe the development and demarcation of anthropology as a set of methods and discipline, before examining the contemporary predilection for interdisciplinarity which underpinned the design of the Marine Systems and Policy programme. Drawing on our ethnographic material, we show how decisions about course structure can reinforce disciplinary boundaries with the effect of limiting opportunities for interepistemic knowledge production, and how the influence of a particular epistemological approach can overshadow others, hindering interdisciplinary learning. Nevertheless, interdisciplinary collaboration can also reveal how formal epistemological distinctions often blur in practice. In the second section, we focus on knowledge practices, outlining social science theories of embodied knowledge and tacit knowledge, and analysing the various challenges and opportunities of teaching and learning such knowledge in an interdisciplinary setting.

\section{Method, Discipline, and Interdisciplinarity}

The development of natural science and anthropological fieldwork methods were intertwined in Europe and North America from the $19^{\text {th }}$ century onwards. Two anthropological fore-founders, Franz Boas and W.H.R. Rivers, were "involved in making the conventions of laboratory science at least as actively as they were helping develop the practices of field work" (Schaffer, 1994: 18). Such conventions included the social structures and material technologies of laboratories (new devices and modes of recording) and the methods of observation, 
measurement, calibration and standardisation (including experimentation on human subjects) (Schaffer, 1994: 20). The latter half of the $1^{\text {th }}$ century saw a shift from armchair scholars using evidence gathered by commercial collectors to scholars conducting fieldwork themselves, mainly in 'pacified colonies' (Kuklick, 2011: 6). Schaffer argues that European scientists saw themselves as "self conscious instruments sent out to measure, observe, detect." (Schaffer, 1994: 28). Early fieldwork, such as conducted by Rivers and his colleagues in the Torres Strait, involved turning "verandahs and beaches into laboratories" (Schaffer, 1994: 36). Here, the anthropologist's body was seen a reliable measuring instrument (Kuklick, 2011: 19).

Interdisciplinarity is thus not new; disciplines have evolved through interdisciplinary phases, and in some cases what were once interdisciplines developed into what are now distinct disciplines (Barry and Born, 2013: 3-4). However, recent decades have seen growing interest in interdisciplinarity, which is presently characterised by the sense that it offers both "a solution to a series of current problems, in particular the relations between science and society, the development of accountability, and the need to foster innovation in the knowledge economy" (Barry and Born, 2013: 1), and "a means of generating questions around which new forms of thought and experimental practice can coalesce" (Barry and Born, 2013: 10). Interdisciplinarity can be understood as an ambitious endeavour "to integrate or synthesise perspectives from several disciplines" (Barry and Born, 2013: 9), particularly to develop new epistemic standards (Fuller, 2004 in Jacobs and Frickel, 2009) and a "life-world problem-oriented research domain" (Zierhofer and Burger, 2007: 53). However, there are practical and pedagogical challenges, as we will show through our ethnographic data. In this paper, 'interdisciplinarity' is more akin to what is sometimes called 'multidisciplinarity': "several disciplines cooperate but work with standard disciplinary framings" (Barry and Born, 2013: 9), or simply "communication and collaboration across academic disciplines" (Jacobs and Frickel, 2009: 44) in which 'disciplinary identity' remains 'distinct' (Morris and Hebden, 2008: 36).

Despite interdisciplinarity's appeal, relatively little attention has been paid to how interdisciplinary relationships develop and whether interdisciplinary collaboration has distinct outcomes; "the literature does not clearly establish the dual propositions that disciplines impede the development of knowledge and that interdisciplinary knowledge is more valuable than that emerging from within disciplines" (Jacobs and Frickel, 2009: 48). Lélé and Norgaard (2005: 968) identify four barriers to interdisciplinarity: 1) reluctance of natural and social scientists to acknowledge the values embedded in their work, exacerbated by the assumption that scientists provide 'objective' advice; 2) adherence and allegiance to disciplinary explanatory models or theories, precluding exploration of other explanations which may work better in a particular context; 3) differences in epistemology and hence in methods, notions of adequate proof, and other fundamental assumptions concerning objectivity/subjectivity and the existence of uncoverable 'absolute truths' versus no absolutely determinable truth (see also Jacobs and Frickel, 2009: 47); and 4) the influence of societal perceptions of the importance of different disciplines, leading to institutional conditions that discourage interdisciplinary knowledge production. Others note the potential for instrumentalism, or even tokenism, in cases in which "social scientists are often positioned as being responsible for the identification and remediation of potential negative downstream consequences of science" (Balmer et al., 2015: 4), tasked with delivering 'outreach' and 'public acceptability' through the 'imagined role' of 'broker', 'translator', mediator', or 'facilitator' between scientists and publics (Balmer et al., 2015: 10).

Existing studies of collaborative fieldwork ventures between science disciplines and anthropology have highlighted their productive potential for insights into respective framings and practices, and identification of new avenues for investigation. Hastrup (2018) examines how collaborations between anthropologists, archaeologists, and biologists on an interdisciplinary field trip to Northwest Greenland became transgressive occasions: unexpected ideas were generated, old taken-for-granted certainties were shattered and understandings overlapped, facilitating the emergence of inter-epistemic knowledge. Through interdisciplinary collaboration, "knowledge engendered in one discipline may be brought to bear on issues emerging in another beyond the simple import of facts (...) collaboration carries a greater potential when the implicated disciplines become visible as human practices, embodied, and emplaced. For the trained anthropologist this is not unlike the collaboration with the subjects in the field." (Hastrup, 2018: 317). Field sites hold different meanings to people according to the knowledge afforded by their respective disciplinary lenses (Hastrup, 2018: 325). Additionally, 'the field' and the 'evidence' which researchers seek therein are accessible to different disciplines at different times, which presents methodological challenges: for archaeology, the High Arctic is only accessible in the snowfree summer months, and the level of sunlight affects what can be seen; for biology, the migratory patterns of animals set a limited time frame for fieldwork; for anthropology, fieldwork can take place in all seasons since social life continues year-round (Hastrup, 2018: 327). For the scientific disciplines, collection and analysis are seen as discrete phases, whereas for anthropology they may be synchronous. The process of identifying and 
narrowing down matters of interest produces the field; "thus fields become scaled to particular questions and concerns" (Hastrup, 2018: 327). In interdisciplinary fieldwork, joint emplacement within the field and the unexpected moments which arise shape researchers' questions and understanding, shifting the disciplines around in profound ways and helping to foster a new sense of the field's potential in the long term (Hastrup, 2018: 330).

Hastrup, Flora and Anderson's (2016) reflections on the same expedition highlight the opportunity for disciplinary self-reflexivity afforded by an interdisciplinary project. On collaboratively reviewing the data that the three disciplines had collected each day, the value of the anthropologists' data was not as obvious as that of the biologists or archaeologists: a local man telling them how to reach one of the islands, versus placing data loggers on little auks, or collecting an agate fluke that would relocate the geographic boundary of a prehistoric culture. They write that "the anthropological knowledge that we could lay claim to seemed implicit in our practices, that is in our ways of moving about in the landscape and of engaging freely in conversation with anybody" (Hastrup et al., 2016: 565). The anthropologists tried to communicate the social nature of anthropology to their colleagues, yet "it was all argument, with no conspicuous 'method", and there were no "results to boast of" from the many conversations with locals, which paved the way for further conversations with and future visits to some of the households (Hastrup et al., 2016: 565). This recalls Ingold's (2011) argument that anthropological experiments do not require elaborate instruments, which allow the investigator to maintain the illusion of absence and objectivity, nor a laboratory which recreates a world designed to highlight only the variables that are subject to investigation; rather, anthropological methods place the investigator in the midst of things, breaking with scientific protocols. Thus, anthropology differs from the sciences in its epistemological approach: while scientists tend to see experiments as a source of raw material to be analysed and transformed into truth at a later stage, anthropologists see material as constructed as they move in particular social spaces of which they are a part and with which they are experimenting (Hastrup et al., 2016). Hastrup, Flora, and Anderson suggest that the presence of the other colleagues who could not 'see' what the anthropologists were doing highlighted Ingold's point that experimentation in everyday life (i.e. anthropological experimentation) is about "enrolling practical activity in the very process of following a train of thought" (Ingold, 2011: 15 in Hastrup et al., 2016: 566).

\section{Disciplinary Boundary-Making}

Our approach differs from these anthropological studies of interdisciplinary fieldwork in focusing on pedagogy rather than research, which allows us to interrogate the processes by which disciplines not only frame themselves and others, but also transmit their knowledge and techniques to students, thus reproducing themselves. Delivering the methods training course involved disciplinary boundary-making alongside growing awareness amongst the instructors at least - of the practical and epistemological affinities across disciplines. The course involved lectures and practical sessions pertaining to what had been defined as the three disciplines (and their methods): marine ecology (point intercept and abundance quadrats), geomorphology (land elevation and basic geological analysis), and social science (participant observation and interviewing). Students were divided into three groups of around five, which rotated to spend a day in turn on each disciplinary area. An objective was to demonstrate the relationship between research questions and research methods in order to equip students to choose field methods appropriate for addressing their research questions. Students then had two days to design and carry out their own mini projects on sustainability in small coral atolls, using whichever methods logically corresponded to their research questions. Most students designed a mini project drawing on methods in which they had some prior experience.

Early on, the students split into three mini project groups, classified according not to project subject, but to disciplinary-based methods: marine, which included all those dealing with water-based research; geomorphology, which was all those doing land-based research; and social, which included any project that involved talking to people. During the formal pedagogical sessions there was little interdisciplinary discussion (particularly as not all staff could attend all sessions, since the different sessions ran concurrently). For example, a session on island resilience was delivered by the geologist, who covered methods to observe variables which indicate resilience: walk or swim around the island to look at environmental gradients, swim to the reef crest to see the potential for sedimentation, look at the sea grass which holds the sediment, walk around the island perimeter to observe the level of erosion, and "get some context of the society". As this was not designed as an interdisciplinary session, there was no scope for the anthropologists to elaborate on how the students might explore (arguably vital) social aspects of resilience. Thus, rather than facilitating the integration or negotiation of disciplinary components, or attempting to overcome the epistemological or ontological assumptions of the established disciplines (Barry and Born, 2013), the structure of the course reinforced disciplinary boundaries: creating, in Wegerifs terms (2007), more of a "monologic" than a "dialogic" space. If adherence to disciplinary approaches, and differences in 
epistemology and hence in methods, are a barrier to interdisciplinary collaboration (Jacobs and Frickel, 2009: 47; Lélé and Norgaard, 2005: 968), perhaps the course's conventional disciplinary framing and boundedness had the effect of closing off opportunities for "transgressive occasions" constituted by more creative, critical engagement resulting in inter-epistemic knowledge (Hastrup, 2018).

\section{Distinctions and Overlaps in Disciplinary Epistemologies}

Through our participant observation in scientific methods instruction, we detected epistemological distinctions, but also cross-disciplinary overlaps and synergies. Social scientists are often taught that quantitative research is broadly deductive, i.e. 'theory-testing', while qualitative research is broadly inductive, i.e. 'theory-generating' (Smith et al., 2009: 54-55). One might therefore expect this to be a fundamental difference with potential for interdisciplinary miscommunications and confusions. In reality, however, much research - whether quantitative or qualitative - combines elements of deduction and induction (Smith et al., 2009: 55, 118). On the field course, the scientists did not begin by outlining hypotheses to be tested through fieldwork (cf. Hastrup et al., 2016). Their course introductions were more reflective of open-ended fieldwork: in the words of the geologist, "when you first arrive you don't know what will be the interesting research questions, so it's a learning process which includes working out what the interesting and tractable questions might be: observing and then start posing questions and developing hypotheses to test". This approach recalls the qualitative methodology of grounded theory, in which data precede theory (Glaser and Strauss, 1967; Strauss and Corbin, 1998), and is not so alien to anthropologists accustomed to asking, "what's going on here?" (Goffman, 1974). The scientists at times also emphasised the subjectivity of the observer with comments like "it's a judgment call", "it's all 'about', [you] don't have to be precise", and "it's not an exact science", rather than attempting to maintain the illusion of objectivity (cf. Hastrup et al., 2016). Thus, the formal propositions associated with the different disciplines often blurred in the practical delivery of the methods training. The scientists presented science not as "the formation of a set of theoretical propositions checked by the simple observation of that world" but rather "a complex network of practical activities which engage with the natural world" (Schaffer, 1994: 9).

Nevertheless, the scientists and social scientists conceptualised data collection and knowledge production differently. For anthropology, knowledge, as Ingold (2014: 391) puts it, "is not built from facts that are simply there, waiting to be discovered and organized in terms of concepts and categories, but that it rather grows and is grown in the forge of our relations with others". Such relations are often complex and unpredictable, requiring negotiation and adaptability. For the scientists, however, knowledge was understood to derive from rigorous (i.e. valid, reliable) data collection, in which the researcher is the (invisible) agent of observation of external, accessible phenomena. This approach, and its extension to the social world, was evident when the marine ecologist proclaimed to the students: "You have full access to the island, including the sea and the people". In fact, the previous day's social science session had taught quite the opposite: that when it comes to people, 'access' does not guarantee data. We had secured permission to interview a representative of the Magoodhoo harbour construction company, but this was withdrawn at the last minute, and the students were left to interview a man whom the island councillor had presented to them as their 'translator'. The students had prepared technical questions about the legislation, commissioning, and construction of the harbour, but the 'translator' was not an expert in the harbour, and could not answer the students' questions, and yet they did not adapt their approach in order to probe his area of interest. Indeed, in all of the interview sessions, many students seemed to relate to research participants as sources of information rather than as people embedded in a socio-cultural context: they often did not reflect on the process of setting up interviews with locals or ask about the interviewee's name, professional identity, or social role, and doggedly stuck to asking questions about their own area of interest even when it became clear that the interviewee did not know or want to talk about that topic.

Additionally, some students had doubts about the usefulness of the social science exercise - one claimed not to have learned anything that could not have been learned from the internet - revealing a focus on outcome (data) rather than process (learning a method). This is reminiscent of the sense during Hastrup et al.'s (2016:565) interdisciplinary fieldwork that the anthropologists had no "results to boast of" from their conversations with locals. Similarly, Bastide's (2011) reflections on teaching anthropology to students of human sciences reveal differences in approaches to process and outcome. Bastide claims human sciences students would not accept that tutorials should leave them with more questions than answers and were annoyed by a lack of clear 'undisputed truth', whereas humanities students were generally more accepting (Bastide, 2011: 65). The notion that there is nothing to be learned by reflecting on the process itself, or a fixed idea about the sort of methodological 'tools' one needs to develop, hampers cross-disciplinary learning. In Djohari's discussion on the challenges of teaching the anthropological critique of development, she shows how development studies 
students were less interested in questioning the broader development agenda, and more intent on looking for "answers, tools, and strategies that can help them do a better job" (2011: 25). She carefully illustrates how this ultimately resulted in despondency generally and a rejection of anthropology specifically (Djohari 2011). These cases highlight differences between the disciplines, the influence of the scientific approach on the students, and the need to expose students unfamiliar with anthropology to ideas about interactions between researchers and research participants as the process through which social knowledge is co-produced (see Ingold, 2014).

As Hastrup (2018) argues, disciplines have contrasting ways of constructing and engaging with 'the field', and the meanings they attach to particular sites are shaped by their particular disciplinary knowledge. For the marine ecologists we were with, the field was primarily the ocean, an area extending beyond the island's land mass into the surrounding reef, and incorporating various depths, and static and mobile forms of life. Their methods involved quantification and classification, using quadrats, transects, line intercepts, and spot counts. The geologists conceptualised the field as the island's landscape, extending below the surface and out into the sea. They were concerned with static and shifting physical structures, and used maps, GPS satellite navigation and way points, lasers and tide measures. The anthropologists conceptualised the field as unbounded, and were concerned, in the vein of multi-sited ethnography (Marcus, 1995), with following people, objects, metaphors, stories, and conflicts. We used pens, notebooks and audio/visual recorders to generate multi-faceted, detailed descriptions of social phenomena. Yet despite our various perspectives and ways of rendering places legible, we all saw the island as in some way evolving, and enduring. In our teaching we all conveyed the idea of the island as a living organism, held together by the symbiotic and generative relationships between multiple actors: the vegetation that preserves the structural integrity of the soil; the coral which dissipates wave energy, preventing it from eroding the beach; the algae that oxygenates the coral; the sea-grass that holds the calcareous red algae which eventually becomes sand; and the social structures, relations, and activities which bring the island, as a place and community, into socio-cultural significance, and shape its physical structures.

\section{Embodied Knowledge, Tacit Knowledge, and Social Interaction}

A subfield of anthropology has examined how specific skills and bodies of knowledge are taught and learned, at the individual and broader social level, as reflected in the concepts of socialisation and enculturation. Questions that guide this work include how non-linguistic manifestations of knowledge, including bodily and perceptual practices, can be recorded, understood, and represented; how new practices emerge and become established as habits; and how the dynamic relations of learning relate to the environment in which learning takes place. Anthropologists have favoured a paradigm of knowledge making, a situated, dialogical and constructive process of engagement between people, things and the environment, over knowledge transmission, which implies a hierarchical, methodical transfer from one individual or group to another (Marchand, 2010: Siv).

Inspired by Edmund Husserl and Maurice Merleau-Ponty, phenomenological anthropologists heralded a shift "away from culture as social rules, or purely cognitive or semiotic structure" (Downey, 2010: S27) toward the role of the body and embodied experience in the constitution of knowledge. With the discipline's reliance on 'being there' (Cohen, 2010: S193), 'cultural immersion', and physical and perceptual measurement (Kuklick, 2011: 19), anthropologists have long recognised the methodological instrumentality of the body. However, phenomenological anthropologists inspired explicit attention to action, enactment, and performance - aspects which are not easily verbalised or subject to reflection (Jackson, 1996; see also Martens et al, 2014) - and revealed that much of the practical knowledge required for being in the world is tacit and embodied (e.g. Bloch, 1991; Bourdieu, 1977, 1990; Csordas, 1997, 1999; Ingold, 2001; Jackson, 1996). This approach distinguishes between "a pre-theoretical and praxical relation to the world-embodied actions of using and doing things in everyday life" and "a contemplative and reflexive relation to the world" (Gray, 2009: 256-7).

The methodological implication of embodiment is that anthropologists are not "motionless intellectual sponges who are only in the field to participate in 'objective' observation" but "students and would-be practitioners, seeking to learn about a new partial reality" and to develop awareness of their own embodied knowledge as a result of cultural experience (Landry, 2008: 63). Thus, according to Landry, anthropologists should resist the urge to document visual observations which seek to "bolster our perceived 'scientific authority", and instead "learn by doing" with our bodies (2008: 56), and "allow our informants to interpret their realities through a sensuous and embodied framework" (2008: 62). In this vein, ethnographies of dance, sports, ritual, musicianship, and crafts have explored how embodied knowledge emerges through imitative learning or apprenticeship in bodily practices (Downey, 2010; Harris, 2007; Landry, 2008; O'Connor, 2005, 2017). Embodiment lies in the bodies of practitioners, but also in the materials and tools required to carry them out, and the physical arrangement of the 
space in which they are practiced (O'Connor, 2017: 218). The apprentice initially pays attention to the tools and techniques, but over time they fade from consciousness and become extensions of the body, or part of what Michael Polanyi (1962) termed 'subsidiary awareness' (O’Connor, 2005: 188).

Meanwhile, sociologists of scientific knowledge have similarly theorised processes of knowledge and skills development, particularly in the context of 'scientific cultures' and scientific experimentation. Like anthropologists, sociologists of scientific knowledge have drawn upon the work of Michael Polanyi (1958) to propose an 'enculturational model' which sees skills transmission as a process of socialisation that is inherently embodied, in opposition to an 'algorithmical model' in which skills transmission is akin to the transfer of information (Pinch et al., 1996: 164). The enculturational model implies that keeping a skill alive requires living practitioners; inscription in texts or other non-human embodiments is not sufficient (Pinch et al, 1996: 165). Sociologists of scientific knowledge have tended to focus on tacit knowledge, which Collins (2001: 72) defines as "knowledge or abilities that can be passed between scientists by personal contact but cannot be, or have not been, set out or passed on in formulae, diagrams, or verbal descriptions and instructions for action", rather than embodied knowledge per se. Others have examined what tacit knowledge is, and how it is generated, used, shared, and withheld, including within the discipline of anthropology itself (Gerholm 1990).

Cambrosio and Keating (1988) argue that the fact that tacit knowledge is not verbalised does not mean that it is by nature non-verbal, inaccessible, non-transmissable, or largely beyond control of scientists. Rather, much of what is left unsaid has the potential to be verbalised but for a variety of reasons remains "unsayable, unthinkable, trivial, secret, or censored" (Cambrosio and Keating, 1988: 246) due to conscious scientific practice. Collins's (2001) classification offers a more comprehensive, nuanced account of both unspoken and 'uncognised' forms of tacit knowledge. He identifies five kinds of tacit knowledge. Concealed knowledge can be intentional or the result of logistics, when a researcher is protective of 'the tricks of the trade' or when publications do not have the space to go into sufficient detail, and can be overcome through a laboratory visit. Mismatched salience is when researchers focus on different variables, with one researcher not realising that the other needs to be told to do things a particular way and the other researcher not knowing the right questions to ask, and can be overcome by the researchers observing each other at work. Ostensive knowledge is information that has to be transmitted physically or bodily, such as through directing, demonstrating, or feeling, rather than through textual or visual representation. Unrecognised knowledge is habitual knowledge that may be passed on without either researcher being aware of its importance, and tends to become recognised and explained as understanding in a particular field of science develops. Uncognised/uncognisable knowledge can only be transmitted through apprenticeship and unconscious emulation, like a native language. Importantly, Collins emphasises the transferability of tacit knowledge through various means, two of which are relevant for this paper: social interaction, such as when a researcher spends time working at another laboratory to learn how peers do things, and making explicit aspects of our knowledge that we did not know we knew. He notes (2001: 85 fn19) that the process of interaction between scientists recalls experiences of anthropological fieldwork: "Native members cannot describe the "takenfor-granted' aspects of their world precisely because they are taken-for-granted, but these can become salient when they are viewed through the eyes of someone to whom they are not familiar". The Marine Field Methods course aimed to develop students' methodological knowledge and skills via the means identified by Collins: instructors sought to make their tacit knowledge explicit, and students followed an example and learned by doing. We describe the processes by which the students and we as participant observers mastered the materiality of particular methods and developed embodied knowledge to highlight how the tacit nature of instructors' knowledge posed challenges for delivering methods training.

\section{Materiality}

The materiality of a method is far from trivial. As professional anthropologists, we become accustomed to decision-making about when and how to deploy recording devices in our fieldwork: under what conditions we might write in notebooks, record people's voices, take photographs, or make films. Teaching methods provides a reminder that this decision-making process and the deployment of particular tools are learned, embodied skills rather than theoretical knowledge. It takes time, effort and exposure to different situations to learn to use recording devices appropriately. Displaying a tension familiar to anthropologists (Jackson, 1989: 9, 51; cf. Ingold, 2014: 387), the students undertaking the participant observation activity during the course frequently found themselves torn between participation (which required abandoning the crutch of recording devices) and recording observations via fieldnotes (which precluded full participation). 
In the case of marine ecology, snorkelling and diving necessitate specialist attire in addition to recording devices. Before the data collection activity, a snorkeler would need to assemble mask, snorkel, and fins, and to don protective clothing such as a wetsuit or rash vest and leggings, neoprene gloves and socks. A diver would additionally require a buoyancy control device, oxygen tank, and regulator. Marine data can be recorded via pencil on a plastic slate; our marine colleagues compared preferences and exchanged tips concerning preferred pencil type (wooden or plastic), the optimum number of sharpened pencils, whether to sharpen both ends of a wooden pencil (thus increasing both the likelihood of having a functioning lead and the risk of accidentally stabbing oneself), how to affix the pencil and a rubber eraser to the slate with string or elastic bands, and whether and how to affix the whole shebang to the researcher's body. Other kit required for specific methods includes a tape measure, a quadrat, an underwater camera, and/or a dive computer. Clutching all of this kit on dry land in the hot and humid climate of the Maldives, it is very difficult to imagine how to keep track of it all, let alone swim, snorkel, or dive safely, avoid damaging coral, and simultaneously record data. But much of this paraphernalia seems to become almost part of one's body in the ocean, and recording data while swimming becomes less challenging as it becomes embodied with practice. This reflects what O'Connor (2017: 218) calls the process of learning to perform "a material and intercorporeal choreography", in which the student's acute awareness of the tools and techniques fades to subsidiary awareness as they become extensions of the body (O’Connor, 2005: 188; see also Bloch, 1991).

Studying geomorphology similarly requires a range of tools and recording devices. Before embarking upon fieldwork, the geologist advised us to bring a backpack, a bottle of water, a plastic slate, two pencils, an A3 map, a notebook, and possibly a camera, but did not give specific instructions about how to manage all of this kit. In the field, it became apparent that carrying all of the recording devices separately precluded actually using any of them to record data. Through trial and error, we found that the solution was to attach the map and the notebook to opposite sides of the slate with elastic bands and to attach the pencils to the slate with string, which meant that it was possible to record data on either the map or the notebook without having to put anything down. We also shared responsibility for carrying and using a laser level and a pole with a target marked on it (onto which to direct the laser), neither of which were compatible with deploying the recording devices, which had to be put away in the backpack or given to another student when one was on laser level or target pole duty. These logistics were a huge distraction during our first outing, and to a great extent, gaining confidence in the method itself correlated with gaining confidence in how to handle the tools. Later, we discussed the challenges that working with kit posed for concentrating on data collection with the geologist, and we explored this with the students, after which others adopted our workarounds. Similarly, halfway through the course, one of the students complained that it seemed impossible to properly clean the pencil marks off our slates using rubber erasers. The dive instructor, who had watched countless students struggle to clean their slates, suddenly revealed the trick is to soak the slates in soapy water and scratch the pencil marks off using handfuls of abrasive sand. This tip may have been too banal to have become a routinised part of the methods training itself, but it made our lives easier (although did not improve our actual data collection or results). These appear to be examples of Collins's (2001) mismatched salience, with the instructors not recognising the importance of the material management of the equipment - something which had surely become habituated for them - and possibly ostensive knowledge, because physical emulation was crucial to mastering the techniques. The limitations of tacit knowledge were in practice overcome through experimentation and social interaction.

\section{Embodiment}

As Collins notes, the experimenter's body can be a 'crucial variable' (2001: 81). But what might be the implications of different disciplinary approaches to the role of the body in methods training? During a briefing on fish survey methods, one of the marine biologists demonstrated how one's eyes should rove from side to side, concluding: "you're a machine ... a fish counting machine". Here, the body was understood to be able to learn a mechanical and replicable process. During geomorphology fieldwork, when the student who was holding the laser level flexed her legs, the geologist reminded us that the person whose role it was to provide a constant reference point should "view themselves as a tripod, as a rock". Here, the body was understood to be both mechanical and stable. Mechanical conceptions of the body are counter-intuitive from an anthropological perspective in which the body is a 'crucial variable' not because it should replicate mechanical processes, but due to its capacity to understand and incorporate the knowledge and behaviours of another (foreign) body.

The corresponding counter-intuitiveness of our anthropological perspective for non-anthropologists, for its part, was evident in student reflections on the course's participant observation activity, which was to spend an hour in the MaRHE Center kitchen learning from local women how to make Maldivian cuisine. Given the language 
barrier - we did not speak Divehi, and our hosts did not speak much English - this was less a verbal activity and more an embodied exercise that entailed observing, imitating, and participating in skilled tasks: 'learning by doing' (Landry, 2008: 56). The women demonstrated and allowed us to take a turn at cracking open coconuts using a stake in the ground (fera), grating coconuts using two types of coconut grater (bunigundi and bunidaati), squeezing coconut milk from grated coconut by hand, washing and cooking rice and lentils with coconut milk, rolling and cooking flatbread (roshi), and sharpening a kitchen knife on a stone. One student sliced his wrists open on the coconut grater (bunigundi); another sliced his thumb open on the coconut stake (fera), and we managed to spill water and rice on the floor and produce lopsided flatbread aplenty. The women were amused by our ineptitude and the students reflected that these were challenging and skilled activities.

We briefed the students on the importance of writing comprehensive, detailed, contextual descriptions of what we had observed and experienced. However, we did not demonstrate the fieldnote-taking process or provide actual examples of different styles and approaches. Despite the embodied and immersive character of the participant observation, the students' fieldnotes often struggled to articulate their bodily experiences as participants and tended to focus instead on what they witnessed or heard as observers. Several students, accustomed to working within a science discipline, spontaneously wrote in the third person rather than the first person, without conveying having been an active participant in the activity. Some individuals made notes in short bullet points rather than a detailed form that would be intelligible at a later date, and others wrote a series of conclusions without specifying how they had reached them. Our briefings had evidently inadequately emphasised the importance of (the documentation of) participation, as distinct from (the documentation of observation. This is no doubt partly due to the limited time available, but is also another example of mismatched salience: we overlooked the demonstrative instruction the students required, and some students assumed that fieldnotes should resemble other forms of note-taking they were accustomed to. But also - as anthropologists know - it is very difficult to articulate embodied experiences in ethnographic writing.

\section{Conclusion}

By sharing our experience of delivering an interdisciplinary research training course we have put forward a case for interdisciplinary collaboration in teaching. Such collaboration offers opportunities for social interaction and self-reflexivity, which are pathways to recognising the taken-for-granted aspects of our knowledge, as, in true anthropological style, we learn to see our familiar methods as strange (Collins, 2001). This process can help us to understand why scientific disciplines may see the 'lack of immediate tangible results' in social science disciplines as a deficiency, to formulate an explanation of how 'results' are often incremental and longer term, and to develop better ways of communicating our raison d'être and the value of our work to others who do not share our tacit disciplinary knowledge. Furthermore, collaborative teaching may help us to develop a more realistic and nuanced understanding of (disciplinary) knowledge. In Hastrup's (2018: 332) words, "we may not get any closer to a complete understanding, but we may become the wiser about the exponential incompleteness of knowledge and stop looking to each other for firm truths that may deliver instrumental solutions to the current challenges of the world."

As we have shown in this paper, however, delivering an interdisciplinary research training course involves a range of challenges, many of which relate to the nature of tacit knowledge. Mismatched salience often occurs as instructors are not aware of their own assumptions and students do not yet know what questions to ask. Uncognised and embodied forms of tacit knowledge need to be learned through apprenticeship, which requires time and effort, trial and error.

It seems to us that a basic starting point for interdisciplinary collaboration is that instructors in any discipline try to develop an awareness of how their tacit knowledge affects the pedagogical process. Through our experience of studying and teaching the interdisciplinary course we became aware that one of our assumptions as anthropologists is that meaning-making should follow an inductive approach, which meant that we avoided overtly direct instruction on the epistemological foundations of the discipline and even some of the methods. Consequently, some students had mixed and/or unclear ideas about some of the methods; for example, the kind of deep insights that participant observation can offer, how to write ethnographic fieldnotes, and how to adapt research questions when presented with an unplanned interview situation. In hindsight, a didactic pedagogical approach involving more explicit, demonstrative and directive teaching, and less of an open-ended voyage of discovery would have benefited students without prior social science exposure. This insight into tacit knowledge implies that practice in delivering methods in an interdisciplinary setting is necessary: even with the best foreplanning and interdisciplinary discussion, it is unlikely that instructors will know what the gaps in their own 
knowledge are until they enter the field. In other words, it is through observing and practicing interdisciplinary teaching that instructors can best understand their own tacit knowledge, and other disciplines. One practical implication of this is that staff retention is advantageous, as instructors develop expertise in how to teach the course over time and with repetition.

Some scholars of interdisciplinary teaching have argued that instructors would benefit from extensive training in theory and methods, first-hand experience in conducting mixed methods projects, and moving "out of their theory/methods comfort zones" (Hesse-Biber 2015: 474), in order to design collaborative interdisciplinary research methods courses (2015: 476). Our ethnography has shown some of the challenges that instructors face in developing methodological expertise in disciplines that are not their own (such as our difficulties in getting to grips with marine ecology and geomorphology paraphernalia). Our findings suggest that instead of enskilling instructors to teach a variety of methods, it may be more beneficial for instructors to teach their own areas of expertise, in dialogue and collaboration with other disciplines. This implies that in order to be successful, courses require multiple teachers, and that disciplinary perspectives do not merge but rather remain distinctive, engaged in earnest dialogue and shared inquiry (Wegerif 2017). Collaborators must be open and communicative about their respective disciplines: not only their differing conceptions of the research problematic, but also challenges in data collection methods, and understandings of what constitutes evidence. Moreover, as Collins argues with regard to articulating methodological challenges in publications, "It is just a matter of admitting that most things that seem easy now were very hard to do first time round, and that some remain hard even for the experienced experimenter" (2001: 82). Given that research methods take years to learn and are often difficult to articulate and to transmit, even for experienced researchers, pragmatic interdisciplinary collaboration cannot require mastery of the methodological approaches of other disciplines, but it certainly benefits from explicitness about and mutual trust in the expertise and potential contributions of one's interdisciplinary collaborators.

Any efforts by collaborating instructors to overcome the challenges we have identified are likely to be in vain if the institutional structures that underpin the course facilitate the dominance of one discipline over another. As the interdisciplinary literature has highlighted, often interdisciplinary endeavours are science-led, with social scientists positioned as secondary participants tasked with evaluation, mediation, or smoothing the path for rollout of scientific objectives (Balmer et al., 2015). For those planning interdisciplinary courses who are serious about interdisciplinarity and addressing global challenges, such structures need to be re-thought. There must be careful planning at an institutional level to allow equal participation of the different disciplines, so that anthropology is understood on its own terms and embedded in the course from the outset.

Finally, it seems to us that the benefit of bringing together instructors whose expertise lies in a particular discipline and set of methods is to support the development of students who can go into the wider world of research and policy aware of the range of methods available to address global problems, rather than becoming specialists in a narrow set of tools. We academic instructors may remain in disciplinary silos, but the opening up of an interdisciplinary dialogic space allows us to effectively train new generations with a broader understanding of the many perspectives and tools at their disposal.

\section{References}

Abbott, A. (2001), Chaos of disciplines, Chicago: University of Chicago Press.

Balmer, A.S., Calvert, J., Marris, C., Molyneux-Hodgson, S., Frow, E., Kearnes, M., Bulpin, K., Schyfter, P., MacKenzie, A., and Martin, P. (2015), 'Taking roles in interdisciplinary collaborations: Reflections on working in post-ELSI spaces in the UK synthetic biology community', Science and Technology Studies, 28(3): 3-25.

Barry, A. and G. Born (eds) (2013), Interdisciplinarity: Reconfigurations of the social and natural sciences. Abingdon, Oxon: Routledge.

Bastide, H. (2011), 'Three challenges in teaching anthropology', Teaching Anthropology, 1(2): 56-67.

Bloch, M. (1991), 'Language, anthropology and cognitive science’, Man (New Series), 26: 183-198.

Bourdieu, P. (1977), Outline of a theory of practice, Cambridge, UK: Cambridge University Press.

--- (1990), The logic of practice, Cambridge, UK: Polity Press. 
Cambrosio, A., and Keating, P. (1988), “'Going Monoclonal”: Art, science, and magic in the day-to-day use of hybridoma technology', Social Problems 35(3): 244-260.

Cohen, E. (2010), 'Anthropology of knowledge’, Journal of the Royal Anthropological Institute, 16(s1): S193-S202.

Collins, H.M. (2001), 'Tacit knowledge, trust and the Q of sapphire’, Social Studies of Science, 31(1): 71-85.

Csordas, T.J. (1997), Sacred self: A cultural phenomenology of charismatic healing, Columbia and Princeton: University Presses of California.

---- (1999), 'Embodiment and cultural phenomenology', in G. Weiss and H.F. Haber (eds), Perspectives on embodiment: The intersections of nature and culture, New York: Routledge, pp. 143-164.

Djohari, N. (2011), “Breaking other people's toys”: Reflections on teaching critical anthropology in development studies', Teaching Anthropology, 1(1): 21-29.

Downey, G. (2010), “'Practice without theory”: A neuroanthropological perspective on embodied learning', Journal of the Royal Anthropological Institute, 16(s1): S22-S40.

Gerholm, T. (1990), 'On tacit knowledge in academia', European Journal of Education, 25(3): 263-271.

Glaser, B.G. and Strauss, A.L. (1967), The discovery of grounded theory: Strategies for qualitative research, Chicago: Aldine.

Goffman, E. (1974), Frame analysis: An essay on the organization of experience,. New York: Harper and Row.

Gray, J. (2009), 'The anthropology of tacit knowledge in the domestic mandala: A case study of Chhetris in the Kathmandu Valley', Occasional Papers in Sociology and Anthropology, 11: 255-278.

Harris, M. (ed) (2007), Ways of knowing: New approaches in the anthropology of knowledge and learning, Oxford: Berghahn.

Hastrup, K. (2018), 'Collaborative moments: Expanding the anthropological field through cross-disciplinary practice', Ethnos, 83(2): 316-334.

----, Flora, J., and Anderson, A.O. (2016), 'Moving facts in an Arctic field: The expedition as anthropological method', Ethnography, 17(4): 559-577.

Hesse-Biber, S. (2015), 'The problems and prospects in the teaching of mixed methods research', International Journal of Social Research Methodology, 18(5): 463-477.

Ingold, T. (2001), The perception of the environment: Essays in livelihood, dwelling and skill, London: Routledge.

---- (2011), Being alive: Essays on movement, knowledge and description, London: Routledge.

---- (2014), 'That's enough about ethnography!', Hau: Journal of Ethnographic Theory, 4(1): 383-395.

Jackson, M. (1989), Paths toward a clearing: Radical empiricism and ethnographic inquiry, Bloomington: Indiana University Press.

---- (1996), 'Introduction: phenomenology, radical empiricism, and anthropological critique', in M. Jackson (ed)

Things as they are: New directions in phenomenological anthropology, Bloomington: Indiana University Press, pp. 1-50.

Jacobs, J.A., and Frickel, S. (2009), 'Interdisciplinarity: A critical assessment', Annual Review of Sociology, 35: 43-65.

Kuklick, H. (2011), 'Personal equations: Reflections on the history of fieldwork, with special reference to sociocultural anthropology', Isis 102(1): 1-33. 
Landry, T.R. (2008), 'Moving to learn: Performance and learning in Haitian Vodou', Anthropology and Humanism, 33(1/2): 53-65.

Lélé, S., and Norgaard, R.B. (2005), 'Practicing interdisciplinarity', BioScience, 55(11): 967-975.

Marchand, T.H.J. (2010), 'Preface', Special Issue: Making Knowledge, Journal of the Royal Anthropological Institute, 16(s1): Siii-Sv.

Marcus, G. (1995), 'Ethnography in/of the world system: The emergence of multi-sited ethnography', Annual Review of Anthropology, 24: 95-117.

Martens, L., Halkier, B., and Pink, S. (2014), 'Researching habits: Advances in linguistic and embodied research practice', International Journal of Social Research Methodology, 17(1): 1-9.

Mills, D., and Spencer, D. (2011), 'Editorial: Teacher or Anthropologist? Pedagogy and Ethnographic Sensibility', Teaching Anthropology, 1(1): 1-2.

Morris, N., and Hebden, J.C. (2008), 'Evolving collaborations: A self-referential case-study of a social/natural sciences collaborative project', Science Studies, 21(2): 27-46.

Nind, M., Kilburn, D., and Luff, R. (2015), 'The teaching and learning of social research methods: developments in pedagogical knowledge', International Journal of Social Research Methodology, 18(5): 455-461.

O'Connor, E. (2005), 'Embodied knowledge: The experience of meaning and the struggle towards proficiency in glassblowing', Ethnography, 6(2): 183-204.

---- (2017), 'Touching tacit knowledge: Handwork as ethnographic method in a glassblowing studio', Qualitative Research, 17(2): 217-230.

Pinch, T., Collins, H.M., and Carbone, L. (1996), 'Inside knowledge: Second order measures of skill', The Sociological Review, 163-186.

Polanyi, M. (1958), Personal knowledge, London: Routledge and Kegan Paul.

---- (1962), Personal knowledge: Towards a post-critical philosophy, Chicago, IL: University of Chicago Press.

Schaffer, S. (1994), From physics to anthropology and back again, Cambridge: Prickly Pear Press.

Smith, K., Todd, M., and Waldman, J. (2009), Doing your undergraduate social science dissertation, London: Routledge.

Strauss, A.L., and Corbin, J. (1998), Basics of qualitative research: Techniques and procedures for developing grounded theory, London: Sage.

Wegerif, R. (2017), 'Dialogic space, and why we need it'. https://www.rupertwegerif.name/blog/dialogic-spacewhy-we-need-it [accessed 23/11/2020]

Wegerif, R., and Mercer, N. (1997). A dialogical framework for investigating talk, in R. Wegerif, and P. Scrimshaw (eds.), Computers and talk in the primary classroom, Clevedon: Multilingual Matters, pp. 49-65.

Zierhofer, W., and Burger, P. (2007), 'Disentangling transdisciplinarity: An analysis of knowledge integration in problem-oriented research', Science Studies, 20(1): 51-74.

\section{Notes}

\footnotetext{
${ }^{\mathrm{i}}$ https://marhe.unimib.it/

ii The Masters programme has undergone some minor changes and was still being offered for students starting in 2021 at the time of writing. See http://www.drps.ed.ac.uk/19-20/dpt/ptmscmarsp1f.htm.
} 
iii For simplicity, since this paper is about interdisciplinary collaboration, we refer to our colleagues by their disciplinary affiliations rather than by name.

\section{Acknowledgements}

We are grateful to Meriwether Wilson ('the marine ecologist') and Sandy Tudhope ('the geologist') for lively conversations about our respective disciplines and interdisciplinary work, and to our fellow instructors and the students alike for tolerating our dual roles as instructors and participant observers. We thank Mairi O'Gorman for her constructive comments on an earlier version of this paper.

\section{Disclosure statement}

No potential conflict of interest was reported by the authors. 